\title{
Intrahippocampal Wortmannin Infusion Enhances Long-Term Spatial and Contextual Memories
}

\author{
Pramod K. Dash, ${ }^{1}$ Sara A. Mach, Sonja Blum, and Anthony N. Moore \\ Department of Neurobiology and Anatomy, The Vivian L. Smith Center for Neurologic Research, \\ The University of Texas Medical School, Houston, Texas 77225, USA
}

\begin{abstract}
The transition from short- to long-term memory involves several biochemical cascades, some of which act in an antagonistic manner. Post-training intrahippocampal administration of wortmannin, a pharmacological inhibitor of phosphatidylinositol 3-kinase, had no effect on memory tested $3 \mathrm{~h}$ later, but improved long-term memory tested $48 \mathrm{~h}$ following the completion of training. This effect was seen in two hippocampus-dependent tasks: the Morris water maze, using both massed and distributed training paradigms, and contextual fear conditioning. The improvement of long-term memory appears to be the result of enhanced consolidation, as wortmannin had no effect on memory recall. These results are consistent with the hypothesis that memory consolidation involves competing processes, and that blockade of an inhibitory constraint facilitates the consolidation process.
\end{abstract}

Declarative memory in humans and spatial and contextual memories in animals are hippocampal-dependent phenomena (Morris et al. 1982; Squire 1992). Neuropsychological experiments have revealed that hippocampal lesions severely impair the ability to acquire declarative memories such as word and face recognition (Zola-Morgan et al. 1986). Likewise, hippocampal lesions and pharmacological interventions in rodents have been shown to cause poor performance in spatial and contextual memory tasks (Morris et al. 1982; Kim et al. 1992; Moser et al. 1993). Although the involvement of the hippocampus in spatial and contextual memory storage is well accepted, the molecular mechanisms underlying memory storage have not been fully delineated.

Biochemical and pharmacological studies have identified a few cascades, including both positive and negative regulators of protein phosphorylation and gene transcription that participate in long-term memory. For example, phosphorylation events initiated by cAMP-dependent protein kinase A (PKA) and extracellular signal-regulated kinase (Erk) are required for long-term memory in both vertebrates and invertebrates (Drain et al. 1991; Zhao et al. 1995; Abel et al. 1997; Atkins et al. 1998; Blum et al. 1999). In contrast, the protein phosphatase calcineurin acts as negative regulator of PKA activity, and its inhibition enhances memory (Malleret et al. 2001). In addition to kinase-phosphatase cas-

${ }^{1}$ Corresponding author.

E-MAIL p.dash@uth.tmc.edu; FAX (713) 500-0621.

Article and publication are at http://www.learnmem.org/cgi/doi/ $10.1101 / \mathrm{lm} .50002$. cades, the balance in activity between positive and negative regulators of transcription has been shown to be critical for plasticity and memory formation (Abel et al. 1998; Soderling and Derkach 2000; Malleret et al. 2001). For example, longterm plasticity in Aplysia californica and long-term memory in Drosophila can be enhanced by increasing the ratio between the activator and the repressor forms of the transcription factors calcium/cAMP response element binding protein (CREB) (Bartsch et al. 1995; Yin et al. 1995). In Aplysia, phosphorylation of the repressor form of CREB (ApCREB2) by Erk decreases its activity and results in conversion of transient facilitation into long-term functional and structural changes, which are correlates of long-term memory (Bartsch et al. 1995). In Drosophila, overexpression of an activator form of CREB facilitates memory consolidation while expression of a dominant-negative form impairs long-term memory (Yin et al. 1994, 1995). Recently, it has been reported that inhibition of phosphatidylinositol 3-kinase (PI3 kinase) impairs long-term memory for fear conditioning and step-down avoidance tasks (Barros et al. 2001; Lin et al. 2001), possibly via a negative regulation of the activity of Erk.

In this report, we show that post-training infusion of wortmannin, an inhibitor of PI3-kinase, into the dorsal hippocampi improved long-term memory in two hippocampusdependent tasks, the Morris water maze and contextual fear conditioning. The enhancing effect of wortmannin on longterm memory storage appears to be the result of increased consolidation rather than improved memory recall. In contrast to previous reports, our results suggest that wortmannin blocks an inhibitory process, thereby facilitating memory consolidation.

LEARNING \& MEMORY 9:167-177 @ 2002 by Cold Spring Harbor Laboratory Press ISSN1072-0502/02 \$5.00

$$
\begin{array}{lllllllllllllll} 
& E & A & R & N & I & N & G & \mathcal{Q} & M & E & M & O & R & Y \\
\text { www.learnmem.org } & & &
\end{array}
$$




\section{RESULTS}

\section{Intrahippocampal Infusion of Wortmannin Decreases Akt Phosphorylation}

Several lines of evidence indicate that the protein kinase Akt is phosphorylated on Ser473 and Thr308 in response to PI3-kinase activation (Vanhaesebroeck et al. 1997). To assess the in vivo efficacy of the PI3-kinase inhibitor wortmannin, the phosphorylation of Akt at Thr308 in the activation domain was measured using a phosphorylation-spe- cific antibody. Animals were infused with either $8.5 \mathrm{ng}$ or 5 $\mu \mathrm{g}$ of wortmannin into one hippocampus and an equal volume of vehicle infused into the contralateral hippocampus of the same animal, acting as an intra-animal control. It is estimated that $8.5 \mathrm{ng}$ and $5 \mu \mathrm{g}$ of wortmannin infused into one hippocampus (estimated volume of $200 \mu \mathrm{L}$ ) would result in equilibrium concentrations of $\sim 100 \mathrm{nM}$ and $58 \mu \mathrm{M}$, respectively. These concentrations were chosen based on previously published reports demonstrating that $100 \mathrm{nM}$ wortmannin is an effective dose for inhibiting PI3-kinase activity in cell culture. In addition, administration of $5 \mu \mathrm{g}$ into the amygdala impaired startle-fear conditioning (Lin et al. 2001). Thirty minutes or $1 \mathrm{~h}$ following infusion, protein samples were prepared and used for Western blotting as described in the Materials and Methods section. Figure 1A shows representative Western blots for phosphoAkt and Akt immunoreactivity following 8.5 ng wortmannin or vehicle administration. The figure shows phospho-Akt immunoreactivity is decreased $1 \mathrm{~h}$ following wortmannin administration compared to the vehicleinfused contralateral side of the same animal. The levels of Akt did not change as a result of wortmannin administration. The summary figure demonstrates that $8.5 \mathrm{ng}$ of wortmannin significantly decreased phospho-Akt immunoreactivity $1 \mathrm{~h}$ postinjection (\% vehicle: vehicle, $100.02 \pm 23.09 \%$; $8.5 \mathrm{ng}$ wortmannin: $35.87 \pm 3.84 \% ; P<0.05$ ), but had no effect on $30 \mathrm{~min}$ postinfusion phospho-Akt levels (Fig. 1B). Similarly, infusion of $5 \mu \mathrm{g}$ of wortmannin also significantly decreased phospho-Akt immunoreactivity $1 \mathrm{~h}$ postinjection (\% vehicle: vehicle, $100.01 \pm$ $16.02 \%$; $5 \mu \mathrm{g}$ wortmannin, $30.18 \pm 9.62 \%$; $P<0.05$ ) (Fig. 1C,D).

\section{Post-Training Infusion of Wortmannin Enhances Context-Specific Fear Memory}

Conditioned emotional response (CER) is a type of Pavlovian fear conditioning in which a conditional stimulus obtains the ability to elicit fear-related responses following pairing with an aversive unconditioned stimulus (US) (Kim et al. 1992; Phillips and LeDoux 1992; Rudy and O'Reilly 1999). Contextual fear conditioning has been shown to be dependent on both hippocampal and amygdaloid function. To determine if wortmannin influences context-specific, long-term memory, animals were trained in the CER

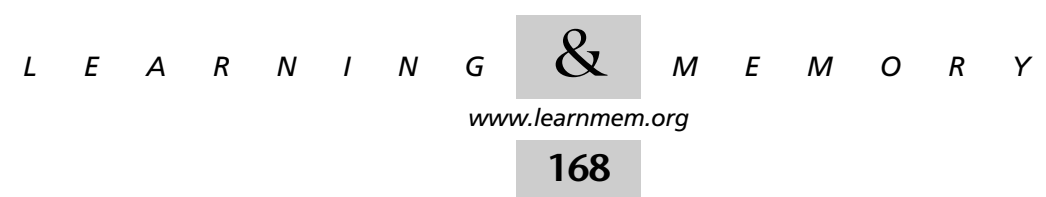


task as described in the Materials and Methods section. Ten minutes following training, bilateral intrahippocampal infusions were performed with either $8.5 \mathrm{ng}$ /hippocampus wortmannin or vehicle. Following a $48 \mathrm{~h}$ consolidation period, animals were tested for both contextual and cued conditioning. Figure $2 \mathrm{~A}$ shows that wortmannin administration significantly improved long-term contextual memory, as indicated by increased freezing to the training chamber compared to vehicle-treated controls. When the same animals were tested for cued conditioning, no significant difference was observed between the two groups (Fig. 2B). As mentioned above, it has been reported that intraamygdaloid infusions of $5 \mu \mathrm{g} /$ amygdala of wortmannin impairs long-term memory for startle-fear conditioning. To examine if there is a similar effect of this dosage of wortmannin following in- trahippocampal infusion, groups of animals were trained and received either $5 \mu \mathrm{g}$ of wortmannin or an equal volume of vehicle. Figure $2 \mathrm{C}$ demonstrates that animals infused with $5 \mu \mathrm{g}$ wortmannin froze significantly more to the context than did their vehicle-infused counterparts when tested $48 \mathrm{~h}$ later for long-term memory. Similar to that seen with the $8.5 \mathrm{ng}$ dose, no effect of the higher concentration of wortmannin was observed on cued freezing behavior (data not shown).

\section{Wortmannin Infusion Does Not Interfere With Contextual Memory Recall}

To examine if the effect of wortmannin administration on long-term memory was a result of enhanced memory formation, or if a lingering effect of the drug improved
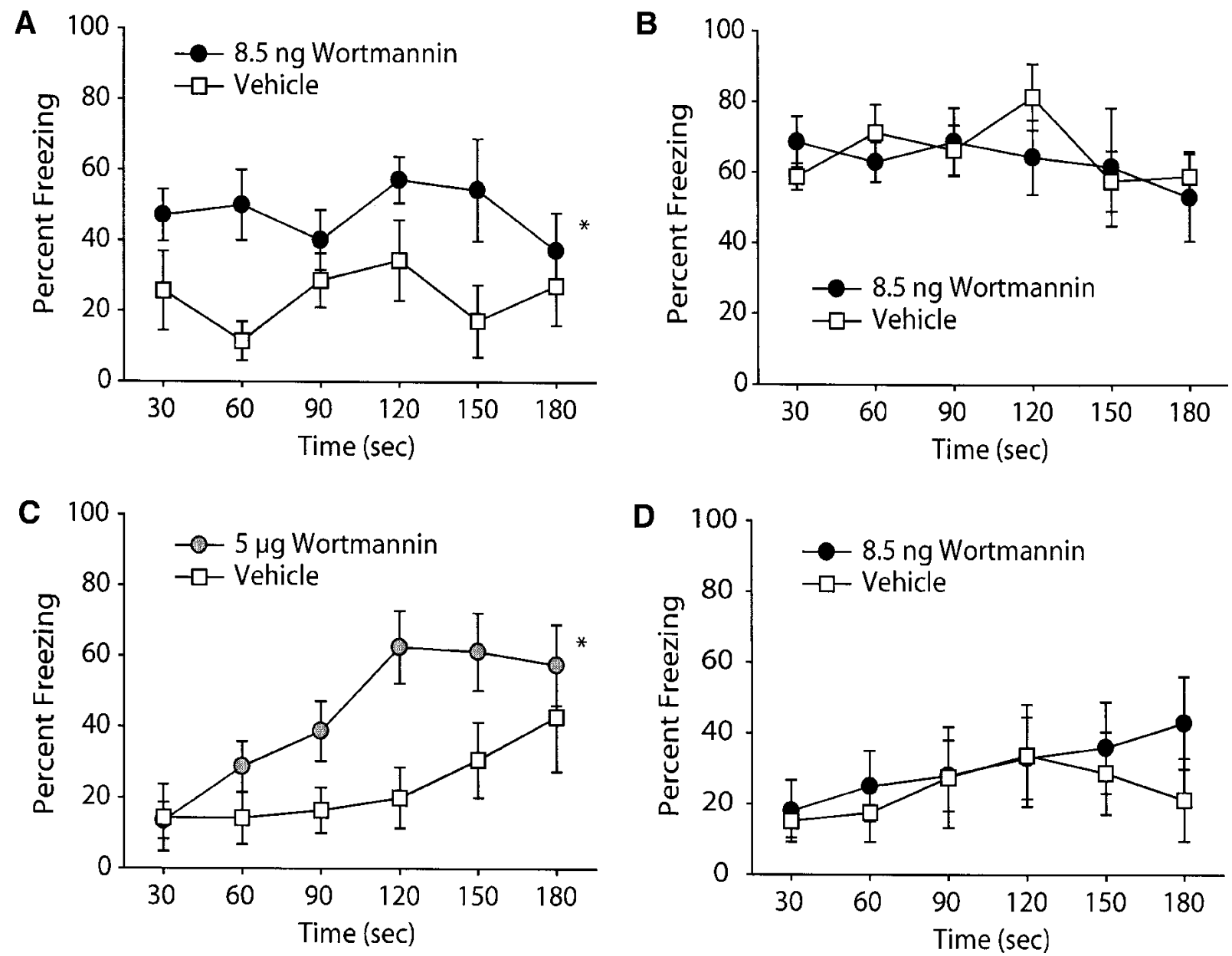

Figure 2 Wortmannin administration improves long-term memory for contextual fear conditioning. Animals were trained in the conditioned emotional response task as outlined in the Materials and Methods section and tested for long-term memory $48 \mathrm{~h}$ later. Post-training administration of $8.5 \mathrm{ng} /$ hippocampus wortmannin $(\mathrm{n}=7)$ improved $(A)$ context-specific long-term memory without any effect on $(B)$ cue-specific long-term memory compared to vehicle-infused controls $(n=7)$. (C) Similar effects on contextual long-term memory were seen following intrahippocampal administration of $5 \mu \mathrm{g} /$ hippocampus wortmannin (vehicle, $\mathrm{n}=7$; wortmannin, $\mathrm{n}=8$ ). $(D)$ When administered $2 \mathrm{~h}$ prior to memory testing, no effect of $8.5 \mathrm{ng} / \mathrm{hippocampus}$ wortmannin was observed (vehicle, $\mathrm{n}=9$; wortmannin, $\mathrm{n}=9$ ). Data are presented as the mean \pm SEM; * indicates significant $(p<0.05)$ differences between the performance curves.

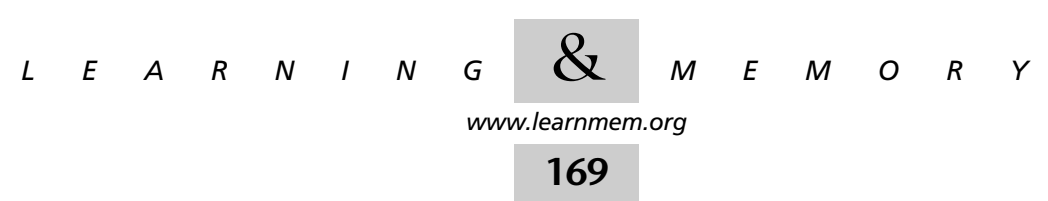


A

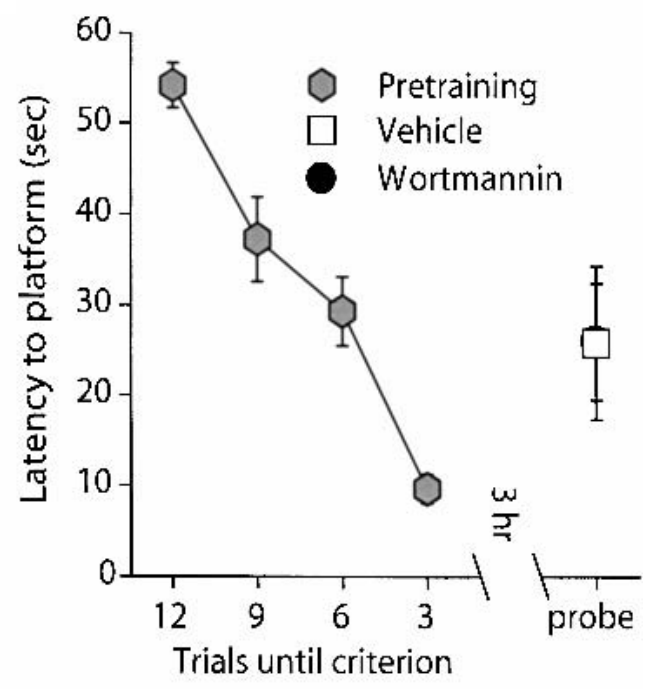

B

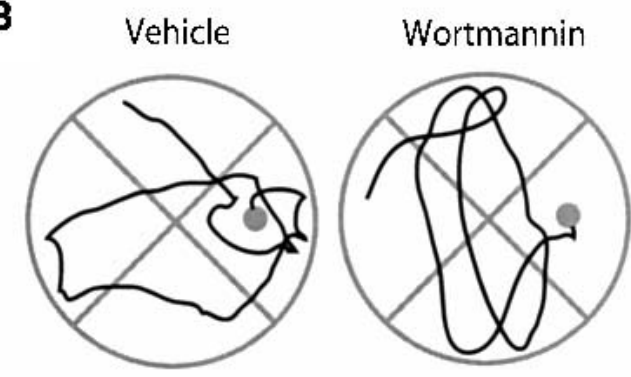

C

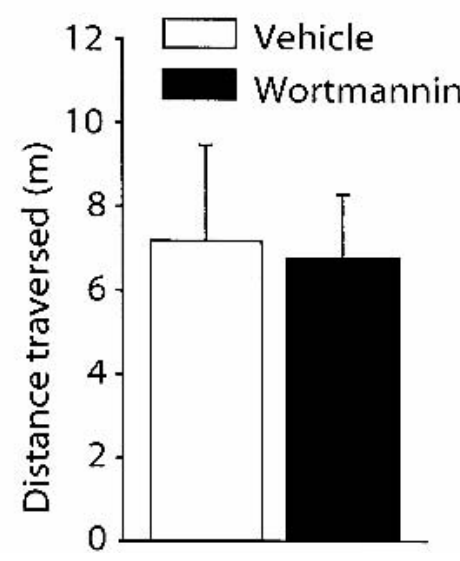

memory recall, animals were trained in the CER task without postinfusion. Two hours prior to recall testing ( $46 \mathrm{~h}$ post-training), animals were infused with either $8.5 \mathrm{ng}$ wortmannin or vehicle and subsequently tested for contextual memory. Figure 2D indicates that recall of contextual memory was not affected by wortmannin administration.
Figure 3 Wortmannin administration does not affect spatial memory tested at $3 \mathrm{~h}$ post-training. Animals were trained in the Morris water maze task as outlined in the Materials and Methods section. Intermediate-term memory was tested by use of a transfer (probe) test $3 \mathrm{~h}$ following the completion of training. (A) Posttraining administration of $8.5 \mathrm{ng} /$ hippocampus wortmannin $(\mathrm{n}=7)$ did not affect the latency to the location of the hidden platform compared to vehicle-infused animals $(\mathrm{n}=7)$. (B) Representative traces from vehicle and wortmannin-infused animals showing the swimming paths prior to the first platform crossing. (C) Similar to the latencies, no significant difference in the path length prior to the first platform crossing was detected between the wortmanninand vehicle-infused animals. Data are presented as the mean \pm SEM.

\section{Post-Training Infusion of Wortmannin Does Not Alter Spatial Memory Tested at $3 \mathrm{Hr}$}

Animals were trained to criterion in the hidden platform version of the Morris water maze as described in the Materials and Methods section. Immediately following training, animals were bilaterally infused with either $8.5 \mathrm{ng} / \mathrm{hippo-}$ campus wortmannin or an equal volume of vehicle. Three hours following the completion of training, spatial memory was tested using a transfer test, in which the platform was removed. Figure $3 \mathrm{~A}$ shows that latencies to the platform were similar between the vehicle- and wortmannin-treated animals, indicating no effect of the drug on intermediateterm memory. Representative swim paths prior to the first platform crossing are shown in Figure 3B for both vehicleand wortmannin-infused animals. Similar to the latencies, the average swim path length prior to the first platform crossing was not different between the two groups (Fig. 3C).

\section{Post-Training Infusion of Wortmannin Enhances Long-Term Spatial Memory}

To determine if wortmannin administration influences longterm spatial memory, animals were trained to criterion in the hidden platform version of the Morris water maze and bilaterally infused with either $8.5 \mathrm{ng} / \mathrm{hippocampus}$ wortmannin or vehicle. Figure $4 \mathrm{~A}$ shows that when the transfer test was performed $48 \mathrm{~h}$ post-training, animals that received wortmannin had significantly shorter latencies to the hidden platform location than did vehicle-treated controls (vehicle: $31.78 \pm 5.05 \mathrm{sec}$; wortmannin: $13.77 \pm 3.32 \mathrm{sec}$; $P<0.05)$. Representative traces obtained from vehicle- and wortmannin-treated animals during the transfer test show the initial swimming path to the platform location (Fig. 4B). Summary data for the path length prior to the first platform crossing is shown in Figure 4C. Consistent with the shorter latencies, wortmannin-infused animals had significantly shorter path lengths than did the vehicle-infused controls (vehicle: $8.11 \pm 1.49 \mathrm{~m}$; wortmannin: $4.12 \pm 1.09 \mathrm{~m}$; $P<0.05)$. There was no difference in the swimming speed

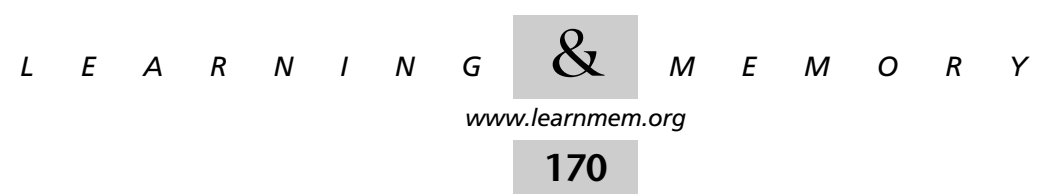


A

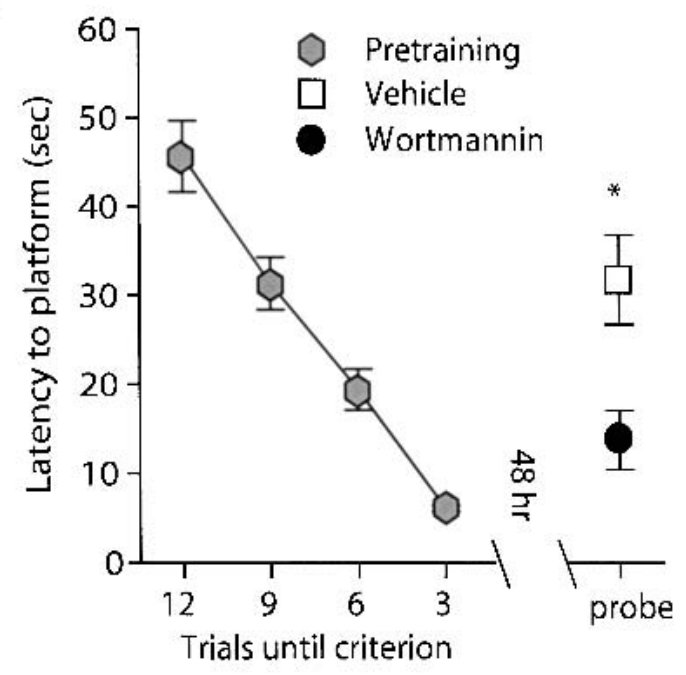

B

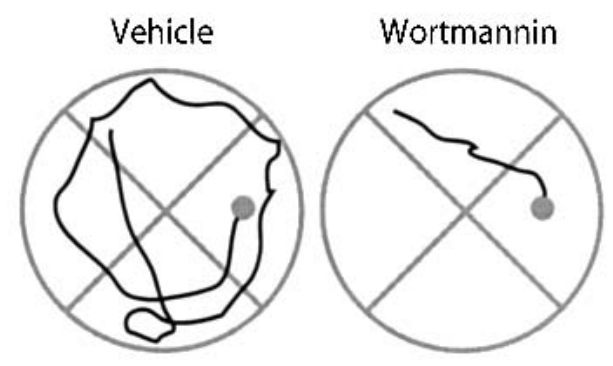

C

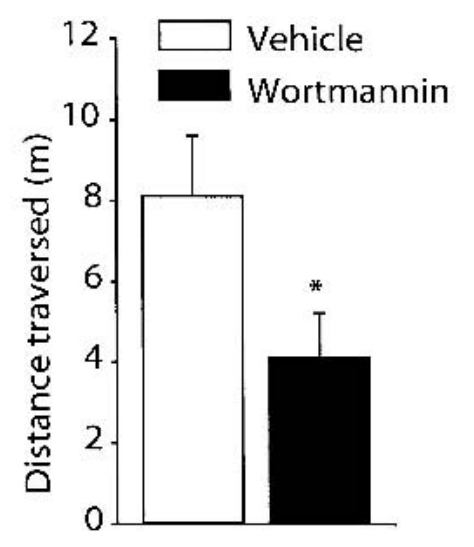

between the two groups (vehicle: $27.40 \pm 0.82 \mathrm{~cm} / \mathrm{sec}$; wortmannin: $25.63 \pm 1.11 \mathrm{~cm} / \mathrm{sec}$; n.s.) during the transfer test.

\section{Intrahippocampal Infusions of Wortmannin Following a Distributed Training Paradigm Also Enhance Long-Term Memory \\ To examine if the facilitative effect of wortmannin is limited} to a massed-training protocol, the effect of wortmannin infusion following a distributed-training paradigm was evalu-
Figure 4 Wortmannin administration significantly improved spatial memory tested at $48 \mathrm{~h}$ post-training. Animals were trained in the Morris water maze task as outlined in the Materials and Methods section. Long-term memory was tested by use of a transfer (probe) test $48 \mathrm{~h}$ following the completion of training. (A) Posttraining administration of $8.5 \mathrm{ng} / \mathrm{hippocampus}$ wortmannin $(\mathrm{n}=16)$ resulted in significantly shorter latencies to the hidden platform location than observed in vehicle-infused controls $(\mathrm{n}=16)$. (B) Representative traces from vehicle and wortmannininfused animals showing the swimming paths prior to the first platform crossing. (C) Similar to the latencies, the path length prior to the first platform crossing was significantly shorter for the wortmannin-infused animals than the vehicle-infused animals. Data are presented as the mean $\pm \mathrm{SEM} ;{ }^{*}, P<0.05$.

ated. Animals were given three trials with a 4-min iti per day for a total of $4 \mathrm{~d}$. A total of 12 training trials were given, comparable to the number of trials used in the massedtraining water maze studies. Following each daily session, animals were infused with either $8.5 \mathrm{ng} / \mathrm{side}$ of wortmannin or vehicle. Figure $5 \mathrm{~A}$ shows that the daily performance of the animals during the training procedure was unaffected by wortmannin administration. Likewise, time to the platform location during the transfer test was also not significantly different between the two groups. To determine if animals treated with wortmannin displayed differences in localization, the number of times animals crossed the platform, as well as the amount of time animals spent in concentric "counter" areas surrounding the hidden platform (Netto et al. 1993), was measured. Figure 5B shows that wortmannin-infused animals crossed the location of the platform significantly more times than did the vehicle-infused controls (vehicle: $0.89 \pm 0.31$ crossings; wortmannin: $2.78 \pm 0.64$ crossings; $P<0.05)$. In addition to platform crossings, the amount of time wortmannin-treated animals spent in "counter" areas centered on the platform, but of larger, diameters ( $2 \mathrm{X}$ and $3 \mathrm{X}$ platform radius) was also significantly greater than controls $(2 \mathrm{X}$ radius: vehicle, 0.87 $\pm 0.27 \mathrm{sec}$; wortmannin: $2.17 \pm 0.52 \mathrm{sec} ; 3 \mathrm{X}$ radius: vehicle, $1.68 \pm 0.37 \mathrm{sec}$; wortmannin: $3.74 \pm 0.84 \mathrm{sec} ; P<0.05)$.

\section{Intrahippocampal Wortmannin Administration Does Not Alter Erk or CREB Phosphorylation}

Several studies have implicated Erk and CREB activities in long-term plasticity and memory (Bourtchuladze et al. 1994; English and Sweatt 1997; Martin et al. 1997; Abel et al. 1998; Blum et al. 1999). To determine the influence of wortmannin infusion on the activities of these two proteins, the phosphorylation of Erk and CREB was examined using phosphorylation-specific and phosphorylation-independent antibodies. The protein samples used to obtain the results shown in Figure 1 were used. Figure $6 \mathrm{~A}$ shows that intrahippocampal administration of $8.5 \mathrm{ng}$ wortmannin did not alter phospho-Erk immunoreactivity compared to the vehicle-treated contralateral side. Similarly, $5 \mu \mathrm{g}$ of wortmannin had no effect on the phosphorylation levels of Erk (Fig.

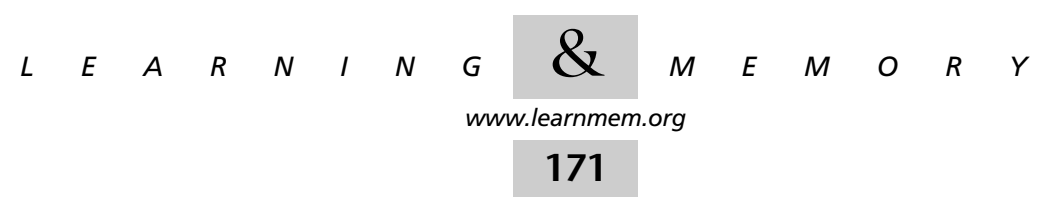


A

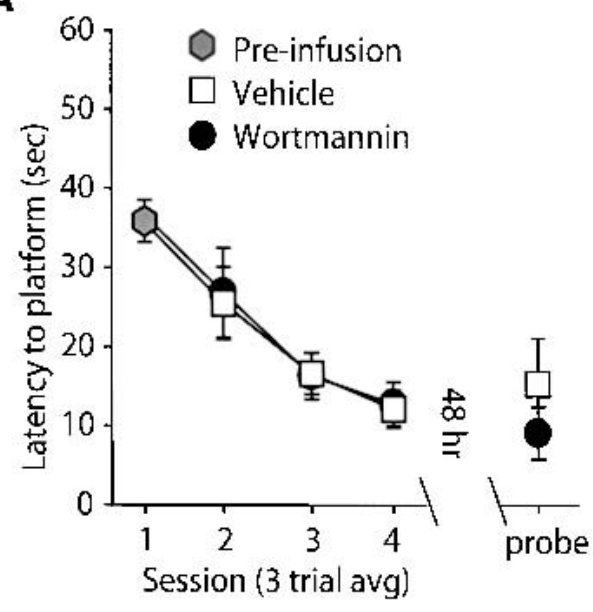

B

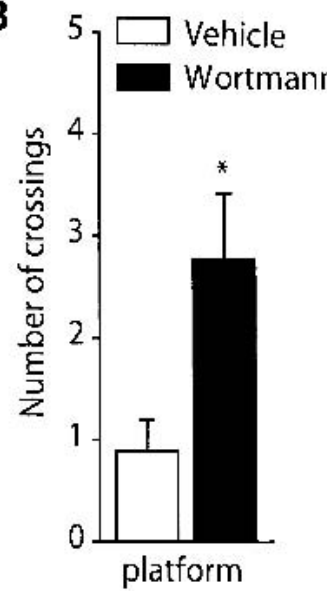

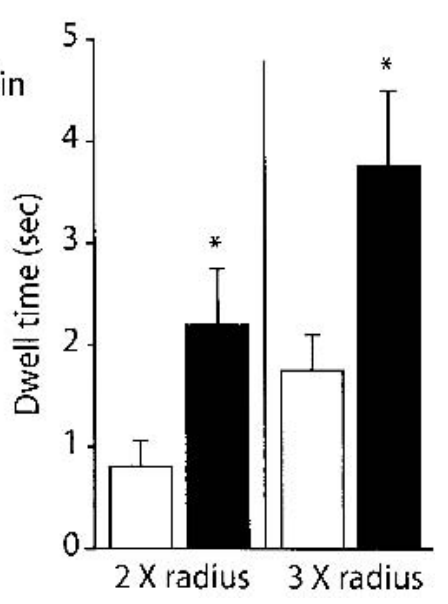

Figure 5 Wortmannin administration improved long-term memory in a distributed-training paradigm. Animals were given one session (consisting of three training trials) each day for four consecutive days. Following each daily session, $8.5 \mathrm{ng} / \mathrm{hippocam}$ pus wortmannin $(n=9)$ or vehicle $(n=9)$ was infused. Retention was tested $48 \mathrm{~h}$ following the last training session. (A) Daily posttraining administration of wortmannin did not alter the latencies to the platform location during the training or during the transfer test. $(B)$ During the transfer test, animals treated with wortmannin crossed the platform location significantly more times than did animals treated with vehicle. "Counter" areas surrounding the platform location but of larger diameters were also explored significantly longer by the wortmannin-infused animals. Data are presented as the mean \pm SEM. $P<0.05$.

6B). When assessed for the immunoreactivity of phosphorylated CREB, no effect of wortmannin administration was detected at either the $8.5 \mathrm{ng}$ or $5 \mu \mathrm{g}$ dose (Fig. 6C,D).

\section{DISCUSSION}

The present study demonstrates that post-training intrahippocampal infusion of wortmannin enhances long-term memory. The enhancing effect of wortmannin on long-term memory storage appears to be the result of increased consolidation rather than improved memory recall. Enhanced memory consolidation was observed in two hippocampusdependent tasks, the Morris water maze using both massed and distributed spatial training protocols, as well as contextspecific fear conditioning. These results suggest that inhibition of an inhibitory cascade, possibly the PI3-kinase cascade, results in enhanced memory consolidation.

Wortmannin has been extensively used as a tool to elucidate the biological functions of PI3-kinase activation. Wortmannin is an irreversible inhibitor with an in vitro $\mathrm{IC}_{50}$ of $\sim 2-5 \mathrm{nM}$, requiring concentrations between 20-50 nM for inhibition of cellular PI3-kinase (D'Onofrio et al. 2001). At concentrations of wortmannin higher than $300 \mathrm{nM}$, it can inhibit other kinases such as a kinase involved in initiation of protein synthesis (mTOR), PI4-kinase, and smooth muscle myosin light-chain kinase (Brunn et al. 1996; Withers et al. 1997; Banin et al. 1998; Izzard et al. 1999). Infusion of $8.5 \mathrm{ng}$ wortmannin into the hippocampus with an estimated volume of $200 \mu \mathrm{L}$ results in an equilibrium concentration of $\sim 100 \mathrm{nM}$, although the concentration proximal to the infusion site is likely to be higher. Therefore, the involvement of a cascade other than one involving PI3-kinase cannot be ruled out in the present study.

Previous studies have shown that massed training gives rise to less robust long-term memory as compared to spaced training, possibly because of the activation of inhibitory cascades. Distinct molecular mechanisms for memory storage have been identified following different patterns of training in several species, including Aplysia californica and Drosophila (Ghirardi et al. 1995; Drier et al. 2002; Sutton et al. 2002). For instance, massed training of Drosophila with no rest intervals between trials results in memory that lasts for 2-3 d. The duration of memory retention in this paradigm can be enhanced by overexpression of atypical protein kinase M (PKM) zeta (free PKC catalytic subunits) (Drier et al. 2002). In contrast, repetitive training with 15-min rest intervals between individual trials results in memory that lasts for up to $7 \mathrm{~d}$ and is unaffected by PKMzeta overexpression. Our results indicate that the longterm memory enhancing effect of wortmannin is not restricted to a specific pattern of training. When animals were trained in a single day using a 4-min rest interval and infused with wortmannin, long-term memory was enhanced when tested $48 \mathrm{~h}$ later. Similarly, long-term memory was also enhanced when animals were trained three trials per day with a 4-min rest interval over a 4 -d period and infused with wortmannin daily after the end of each training session. However, the significant changes in performance differed between the two training conditions. Following the 1-d training experiments, significant differences in latency to the platform were observed during the transfer test (Fig. 4). In contrast, wortmannin administration following each of the four daily training sessions did not result in decreased

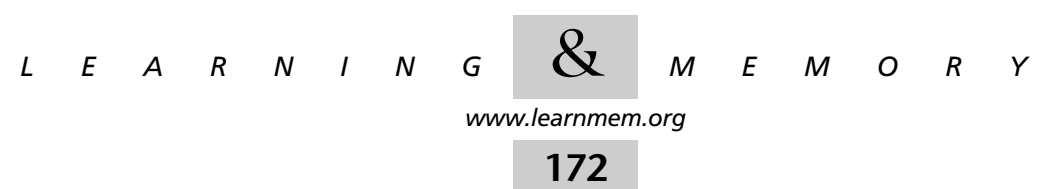


A

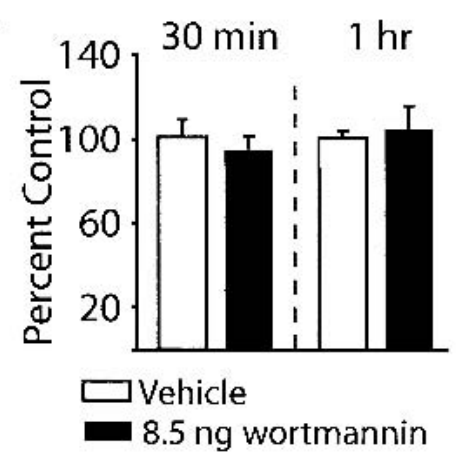

C

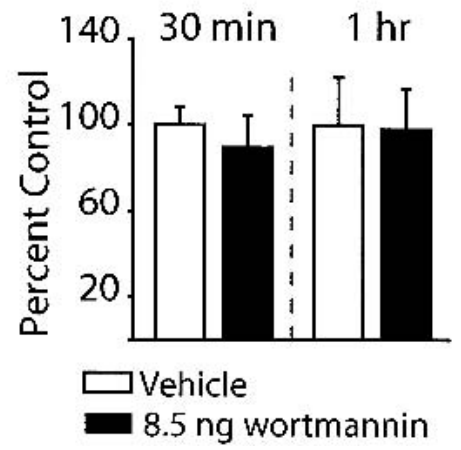

B
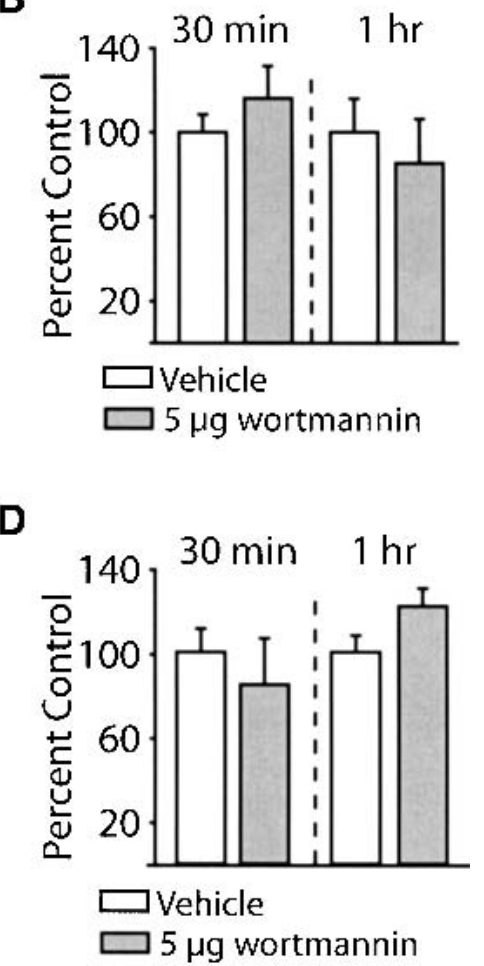

Figure 6 Intrahippocampal administration of wortmannin did not alter Erk or the calcium/CAMP response element binding protein (CREB) phosphorylation. The phosphorylation levels of Erk and CREB were investigated following infusion of 8.5 ng (or $5 \mu \mathrm{g}$ ) wortmannin into one hippocampus and compared to the vehicleinfused contralateral side of the same animal. Summary data showing the levels of phospho-Erk immunoreactivity were not affected by either $(A) 8.5 \mathrm{ng} /$ hippocampus or $(B) 5 \mu \mathrm{g} /$ hippocampus wortmannin administration. Similarly, phospho-CREB immunoreactivity was also unaffected by either $(C) 8.5 \mathrm{ng} /$ hippocampus or $(D) 5$ $\mu \mathrm{g} / \mathrm{hippocampus}$ wortmannin administration. Data are presented as the mean \pm SEM from three independent experiments.

latencies during training or during the transfer test. However, during the transfer test, animals treated with wortmannin crossed the platform location significantly more times and spent significantly more time exploring "counter" areas than did vehicle-treated controls (Fig. 5b). Although latency to platform is used as a measure of spatial memory, it does not reflect the degree to which rats are able to localize to the target location (for review, see Hodges 1996). In a report by Gallagher et al., the authors describe swimming paths that are similar in latency to the first platform crossing but clearly different in their overall proximities to the platform, and suggest the need for measures to determine localization differences other than quadrant preferences (Gallagher et al. 1993). The time spent in "counter" areas centered on the platform has been shown to be an effective measure for examining search perseverance and indicates the degree of spatial localization (Netto et al. 1993). Thus, although the wortmannin and vehicle-treated animals were both capable of initially crossing the hidden platform with similar latencies, the wortmannin animals displayed a stronger spatial bias resulting in more intense searching within the area immediately surrounding the platform. Following the first platform approach, control animals appear to resort to a less defined search strategy that resulted in fewer platform crossings and less time spent searching in the immediate vicinity of the platform.

The role of PI3-kinase in memory and the relationship between long-term memory and long-term potentiation (LTP) is only beginning to be explored. For example, Sanna et al. (2002) demonstrate that the expression, but not the induction or maintenance, of LTP at Schaffer collateral/commissural fiber-CA1 synapses in rat hippocampal slices is dependent on PI3-kinase activity. In contrast, a study by Raymond et al. (2002) suggests that the maintenance of LTP can be blocked by PI3-kinase inhibitors, although interpretation may be restricted as wash-out studies were not performed. A role for PI3-kinase has also been suggested for LTP at the perforant path-granule cell synapses. In these studies, inhibition of PI3-kinase activity abated glutamate release and impaired the expression of LTP (Kelly and Lynch 2000). Although dissociations between the mechanisms underlying LTP and longterm spatial memory have been observed (Jun et al. 1998), these studies suggest that PI3-kinase activity may facilitate long-term hippocampusdependent memory. However, our results suggest that PI3-kinase plays an antagonistic, not facilitory, role in long-term spatial and contextual memories. This effect was only observed on long-term memory, as memory recall or memory tested $3 \mathrm{~h}$ following the training was unaffected by wortmannin administration. These results contrast with a previous report using intrahippocampal administration of the PI3-kinase inhibitor LY294002 and a step-down avoidance task in which impaired acquisition, short-term memory, long-term memory, and the retrieval of long-term memory was observed (Barros et al. 2001). Furthermore, deficits in longterm fear conditioning were found following intraamygdaloid infusion of high concentrations of wortmannin $(5 \mu \mathrm{g})$, although no deficits were detected on short-term memory (Lin et al. 2001). Interestingly, in this report, a lower concentration of wortmannin $(0.5 \mu \mathrm{g})$ appeared to enhance long-term fear memory, an effect that was not statistically significant possibly because of the relatively small $(n=6)$ number of animals tested. Although the reasons for these differences in PI3-kinase action are not clear at present, it suggests that different biochemical mechanisms may be activated by PI3-kinase that modulate long-term memory. For

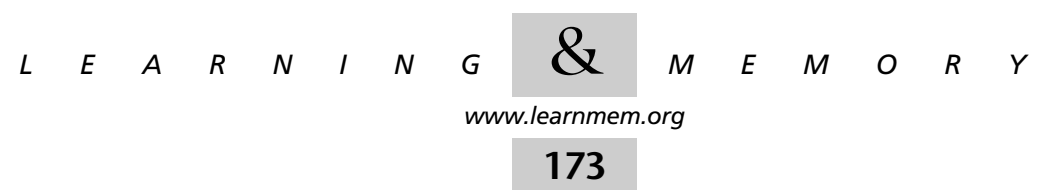


example, it has been reported that the binding of NGF to TrkA receptors leads to the activation of PI3-kinase resulting in the activation of B-Raf and increases in Erk activity (York et al. 2000). In contrast, insulin-like growth factor-1 has been reported to reduce Erk activity via its activation of PI3-kinase and the subsequent phosphorylation of Raf-1 by Akt (Moelling et al. 2002). Lin et al. (2001) observed that wortmannin blocked the forskolin-induced activation of Erk that is associated with late-phase long-term potentiation (LLTP), and suggested that PI3-kinase may play a stimulatory role upstream of Erk and CREB via Akt. Our previous report examining the role of Erk in long-term memory illustrated that Erk activation occurred within 5 min of water maze training and that delayed administration ( $1 \mathrm{~h}$ post-training) of the MEK inhibitor PD098059 had no effect on long-term memory (Blum et al. 1999). Thus, it is unlikely that the decrease in Akt activity we observed at $1 \mathrm{~h}$ postinfusion could alter the Erk signaling that occurs immediately following water maze training. Future experiments aimed at identifying the signaling cascades influenced by wortmannin administration will help elucidate the possible points of interaction between established memory-related cascades and the PI3-kinase cascade following behavioral training.

The activation of PI3-kinase as a result of behavioral training can modulate subsequent intracellular signaling cascades in a complex manner. For example, the PH domain of 3'-phosphoinositide-dependent protein kinase-1 (PDK-1) binds PI3 with high affinity. PDK-1 phosphorylates downstream kinases such as Akt, protein kinase $\mathrm{C}$ (PKC) isoforms (conventional, atypical, and novel), p7056K, and PKA, leading to enhanced activity levels (for review, see Vanhaesebroeck et al. 1997). Thus, the inhibition of PI3-kinase activity by wortmannin would result in reduced PDK-1 activity, which could result in decreased activity of one or more of the downstream kinases. Increases in PI3 levels as a result of behavioral training may also cause structural and functional alterations. Structural changes such as increases in synapse number, varicosities, and branch points are commonly associated with long-term memory storage. Several actin-binding proteins, such as gelsolin, profilin, and villin, contain basic amino-acid regions and bind phosphoinositides including PI3 (Toker and Cantley 1997). For instance, binding of PI3 to the actin-capping protein gelsolin causes release of gelsolin from actin filaments, which results in extension of these filaments (Chellaiah and Hruska 1996). In addition, D3 phosphoinositides bind to the FYVE domain that is present in several membrane proteins involved in regulation of membrane trafficking (Gaullier et al. 1998; Gillooly et al. 2001). In addition to their lipid kinase activities, class I $\mathrm{PI} 3$-kinase isoforms also exhibit serine/threonine protein kinase activity (for review, see Hunter 1995). For example, the $\mathrm{p} 100 \alpha$ catalytic subunit phosphorylates its regulatory subunit (p85) in the inter-SH2 domain (Carpenter et al. 1993). This decreases the binding of the regulatory subunit to activated receptors, possibly acting as a negative feedback mechanism to terminate the signaling cascade. Because wortmannin is equally effective in inhibiting class I, II, and III PI3-kinase isoforms, the present study cannot determine if the effect of wortmannin on long-term memory is due to decreased PI3 production or due to inhibition of direct protein phosphorylation. The inhibition of PI3-kinase could therefore alter memory consolidation at multiple steps. The findings presented in this report support the hypothesis that behavioral training activates both positive and negative regulators of memory (Abel et al. 1998) and suggests that wortmannin blocks a negative constraint on spatial and contextual memory consolidation.

\section{MATERIALS AND METHODS}

\section{Materials}

Long-Evans rats (250-280 g) were purchased from Charles River Laboratories. Phospho-Erk (Thr202/Tyr204), Erk, phospho-CREB (Ser133), CREB, phospho-Akt (Thr308), and Akt antibodies were obtained from Cell Signaling Technologies. Wortmannin was purchased from Calbiochem.

\section{Intrahippocampal Infusion and Drug Preparation}

All protocols involving the use of animals are in compliance with the National Institutes of Health's Guide for the Care and Use of Laboratory Animals and approved by the Institutional Animal Care and Use Committee. Rats were anesthetized using $4 \%$ isoflurane with a $2: 1 \mathrm{~N}_{2} \mathrm{O}: \mathrm{O}_{2}$ mixture and then maintained with a $2 \%$ isoflurane/2:1 $\mathrm{N}_{2} \mathrm{O}: \mathrm{O}_{2}$ mixture via a face mask. Bilateral guide cannulae, aimed at the dorsal hippocampus (AP $-3.3 \mathrm{~mm}, \mathrm{~L} \pm 2.0 \mathrm{~mm}$ from bregma and $\mathrm{V}-1.5 \mathrm{~mm}$ from the dura), were implanted. The rats were then allowed to recover in their home cages for 10-12 d. During infusion, the injection cannulae extended $1.5 \mathrm{~mm}$ beyond the tips of the guides, yielding a total depth of $3.0 \mathrm{~mm}$ below the dura. Stock solutions of wortmannin were prepared by dissolving in DMSO. Prior to infusion, wortmannin was diluted in sterile saline to give either a $5.0 \mathrm{mg} / \mathrm{mL}$ or $8.5 \mu \mathrm{g} / \mathrm{mL}$ solution. Vehicle-treated animals were infused with saline and an amount of DMSO corresponding to that used to dissolve the drug. All injections $(1 \mu \mathrm{L} /$ hippocampus of either drug or vehicle) were performed in freely moving animals at a rate of $0.25 \mu \mathrm{L} / \mathrm{min}$ using a dual syringe infusion pump (Stoelting).

\section{Preparation of Protein Extracts}

To investigate the affect of wortmannin administration on Erk, Akt, and CREB phosphorylation, animals were infused with either $8.5 \mathrm{ng}$ or $5 \mu \mathrm{g}$ wortmannin into one hippocampus while an equal volume of vehicle was infused into the contralateral hippocampus of the same animal. This allows the determination of changes in Erk, Akt, and CREB activities by comparison to an intraanimal control. At 30 min or $1 \mathrm{~h}$ postinfusion, animals were killed and the hippocampal tissues were quickly removed while submerged in ice-cold artificial cerebral spinal fluid (10 mM HEPES pH 7.2, $1.3 \mathrm{mM} \mathrm{NaH}_{2} \mathrm{PO}_{4}, 3$ $\mathrm{mM} \mathrm{KCl}, 124 \mathrm{mM} \mathrm{NaCl}, 10 \mathrm{mM}$ dextrose, $26 \mathrm{mM} \mathrm{NaHCO}_{3}$, and 2 $\mathrm{mM} \mathrm{MgCl}_{2}$ ) containing phosphatase inhibitors $(2 \mathrm{mM} \mathrm{NaF}, 2 \mathrm{mM}$ sodium molybdate, and $1 \mathrm{mM} \mathrm{Na}_{3} \mathrm{VO}_{4}$ ). Two-millimeter in diameter

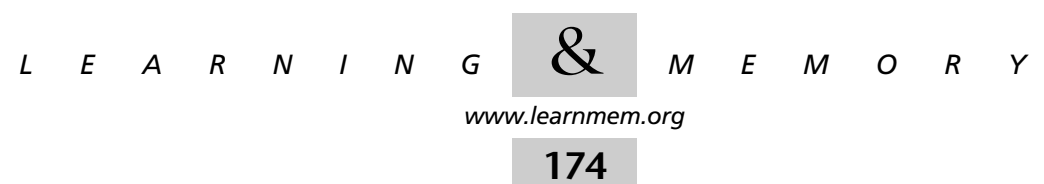


tissue punches were taken surrounding the site of infusion. Tissue punches were separately homogenized in 10 volumes of $10 \mathrm{mM}$ Tris/HCl (pH 7.4), 1 mM EGTA, 1 mM EDTA, 0.5 mM DTT, $0.5 \mathrm{mM}$ PMSF, $10 \mu \mathrm{g} / \mathrm{mL}$ leupeptin, and phosphatase inhibitors ( $2 \mathrm{mM} \mathrm{NaF}$, $2 \mathrm{mM} \mathrm{NaPP}, 0.1 \mu \mathrm{M}$ okadaic acid, and $1 \mathrm{mM} \mathrm{Na}_{3} \mathrm{VO}_{4}$ ). After 20 strokes in a motor-driven Teflon-glass homogenizer, the sample was aliquoted and immediately frozen at $-80^{\circ} \mathrm{C}$.

\section{Western Blots}

The amount of protein in each sample was measured using a Bradford assay with BSA as the standard. Samples were prepared by boiling in sample buffer and equal amounts of protein were resolved in a $10 \%$ Tris/Tricine SDS-PAGE gel and transferred to an Immobilon-P (Millipore) membrane using a semidry transfer apparatus (Millipore). Membranes were blocked overnight in 5\% BSA in TBST (10 mM Tris/HCl [pH 7.9], $150 \mathrm{mM} \mathrm{NaCl}, 0.05 \%$ Tween-20) and incubated with $0.2 \mu \mathrm{g} / \mathrm{mL}$ of primary antibody for $3 \mathrm{~h}$ at room temperature. Membranes were washed five times for $10 \mathrm{~min}$ each in TBST. Immunoreactivity was visualized by an alkaline-phosphatase-conjugated secondary antibody and a CDP-Star chemiluminescence substrate (New England Biolabs). The quantification of the immunoreactive bands was carried out utilizing a BioRad Model GS-670 Imaging Densitometer. Western blots using phosphorylation-specific antibodies were normalized for protein levels and verified for migration by reprobing with phosphorylation-independent antibodies. Prior to reprobing, blots were stripped by two 10-min washes in a buffer containing $62 \mathrm{mM}$ Tris- $\mathrm{HCl} \mathrm{pH} 6.8,2 \%$ SDS and $100 \mathrm{mM} \beta$-mercaptoethanol at $60^{\circ} \mathrm{C}$. The membranes were then washed extensively with TBST and reblocked overnight in 2\% BSA at room temperature. Western blots for total Erk, CREB, or Akt were carried out as described above.

\section{Behavioral Training and Testing}

All behavioral protocols were performed by an experimenter who was kept blind to the treatment schedule.

\section{Conditioned Emotional Response}

Animals were trained in the CER task using a foot shocker and training cage obtained from Coulborne Instruments. Animals were given two consecutive training trials. Animals were given two CSUS pairings with an iti of 2 minutes. The training began with a 2-minute exploration period in which the animal was allowed to familiarize itself with the context followed by a 30 -second tone (CS). A $1.0 \mathrm{~mA}$ foot shock was used as the US during the last 2 seconds of tone presentation. Animals remained in the training chamber for the 2-minute iti followed by the onset of the second CS-US pairing. Ten minutes following the completion of training, animals were bilaterally infused with either drug (8.5 $\mathrm{ng}$ or $5 \mu \mathrm{g}$ wortmannin) or an equal volume of vehicle as described above. For ease in handling, a 10-min interval between completion of training and infusion was utilized. Following infusion, animals were returned to their home cages and allowed to rest until retention testing. For contextual testing, animals were placed in the conditioning chamber for $3 \mathrm{~min}$ and freezing behavior was monitored at 3 -sec intervals. Freezing was defined as refraining from all movement except for that used in respiration. For testing of cued conditioning, animals were placed in a distinctly different environment for $2 \mathrm{~min}$. The tone was then presented for $3 \mathrm{~min}$ during which freezing behavior was measured. The data obtained in 10, 3-sec recording intervals was averaged for each animal to give a percent time freezing over a $30 \mathrm{sec}$ period. For experiments involving the effect of wortmannin on recall, animals were trained as described above, but not infused. Two hours prior to retention testing, animals were bilaterally infused with $8.5 \mathrm{ng}$ wortmannin or an equal volume of vehicle. Contextual and cued testings were carried out as described above.

\section{Morris Water Maze Training}

Cannulated animals were trained in the hidden platform version of the Morris water maze task (Morris et al. 1986; Dixon et al. 1994) with an intertrial interval (iti) of $4 \mathrm{~min}$ until they could locate the platform three consecutive times under 10 sec (Blum et al. 1999). Animals that failed to reach this criterion by trial 13 were eliminated from the study. Each trial was initiated by placing the animal in one of four randomly chosen locations facing the wall of the tank. Animals were allowed to search for the hidden platform for a period of $60 \mathrm{sec}$. If an animal failed to find the platform, it was placed there by the experimenter. Animals were allowed to remain on the platform for a period of $30 \mathrm{sec}$ before being returned to a warming cage between trials. Once criterion was reached, animals were bilaterally infused with either drug or vehicle as described above. Following the completion of training, animals were returned to their home cages until retention testing. Animals were tested for retention by a transfer test in which the hidden platform was removed from the maze and animals were allowed to search for a period of $60 \mathrm{sec}$. Movement within the maze was monitored using a video camera linked to tracking software (Chromotrack, San Diego Instruments). The time to platform was calculated as the latency for each animal to cross the site at which the hidden platform was located during training. Using the tracking software, swimming speed was calculated by dividing the cumulative total distance $(\mathrm{cm})$ traversed in each zone by the cumulative dwell time (Hagiwara et al. 1993).

\section{Statistical Analysis}

Statistical significance was determined by either a repeated-measures ANOVA followed by appropriate post-hoc analysis or by a two-tailed student's t-test for unpaired variables. Data were considered significant at $P \leq 0.05$. Statistical analysis was performed using the integrated optical densities for Western blots or latencies and percent freezing for behavior.

\section{ACKNOWLEDGMENTS}

We thank Dr. Jim Knierim and April Hebert for their comments, and Melanie Moody for her expert technical assistance. This work was supported by a grant (MH49662, NS35452) from the National Institutes of Health.

The publication costs of this article were defrayed in part by payment of page charges. This article must therefore be hereby marked "advertisement" in accordance with 18 USC section 1734 solely to indicate this fact.

\section{REFERENCES}

Abel, T., Nguyen, P.V., Barad, M., Deuel, T.A., Kandel, E.R., and Bourtchouladze, R. 1997. Genetic demonstration of a role for PKA in the late phase of LTP and in hippocampus-based long-term memory. Cell 88: 615-626.

Abel, T., Martin, K.C., Bartsch, D., and Kandel, E.R. 1998. Memory suppressor genes: Inhibitory constraints on the storage of long-term memory. Science 279: 338-341.

Atkins, C.M., Selcher, J.C., Petraitis, J.J., Trzaskos, J.M., and Sweatt, J.D. 1998. The MAPK cascade is required for mammalian associative learning. Nat. Neurosci. 1: 602-609.

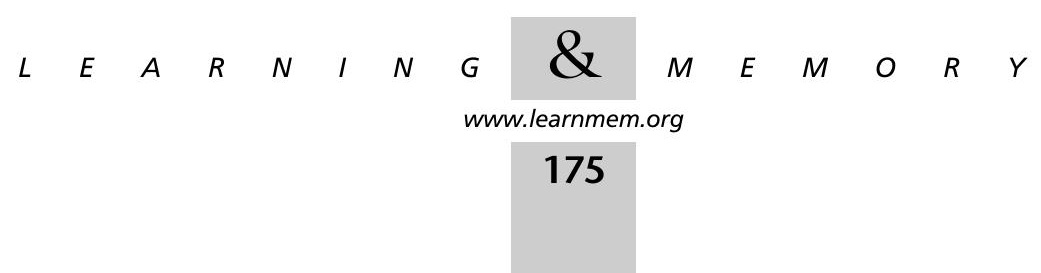


Banin, S., Moyal, L., Shieh, S., Taya, Y., Anderson, C.W., Chessa, L., Smorodinsky, N.I., Prives, C., Reiss, Y., Shiloh, Y. et al. 1998. Enhanced phosphorylation of p53 by ATM in response to DNA damage. Science 281: 1674-1677.

Barros, D.M., Mello e Souza, T., de Souza, M.M., Choi, H., DeDavid e Silva, T., Lenz, G., Medina, J.H., and Izquierdo, I. 2001. LY294002, an inhibitor of phosphoinositide 3-kinase given into rat hippocampus impairs acquisition, consolidation and retrieval of memory for one-trial step-down inhibitory avoidance. Behav. Pharmacol. 12: 629-634.

Bartsch, D., Ghirardi, M., Skehel, P.A., Karl, K.A., Herder, S.P., Chen, M., Bailey, C.H., and Kandel, E.R. 1995. Aplysia CREB2 represses long-term facilitation: Relief of repression converts transient facilitation into long-term functional and structural change. Cell 83: 979-992.

Blum, S., Moore, A.N., Adams, F., and Dash, P.K. 1999. A mitogen-activated protein kinase cascade in the CA1/CA2 subfield of the dorsal hippocampus is essential for long-term spatial memory. $J$. Neurosci. 19: 3535-3544.

Bourtchuladze, R., Frenguelli, B., Blendy, J., Cioffi, D., Schutz, G., and Silva, A.J. 1994. Deficient long-term memory in mice with a targeted mutation of the cAMP- responsive element-binding protein. Cell 79: 59-68.

Brunn, G.J., Williams, J., Sabers, C., Wiederrecht, G., Lawrence, Jr., J.C., and Abraham, R.T. 1996. Direct inhibition of the signaling functions of the mammalian target of rapamycin by the phosphoinositide 3-kinase inhibitors, wortmannin and LY294002. EMBO J. 15: 5256-5267.

Carpenter, C.J., Auger, K.R., Duckworth, B.C., Hou, W.M., Schaffhausen, B., and Cantley, L.C. 1993. A tightly associated serine/threonine protein kinase regulates phosphoinositide 3-kinase activity. Mol. Cell. Biol. 13: 1657-1665.

Chellaiah, M. and Hruska, K. 1996. Osteopontin stimulates gelsolin-associated phosphoinositide levels and phosphatidylinositol triphosphate-hydroxyl kinase. Mol. Cell. Biol. 7: 743-753.

D’Onofrio, M., Cuomo, L., Battaglia, G., Ngomba, R.T., Storto, M., Kingston, A.E., Orzi, F., De Blasi, A., Di Iorio, P., Nicoletti, F. et al. 2001. Neuroprotection mediated by glial group-II metabotropic glutamate receptors requires the activation of the MAP kinase and the phosphatidylinositol-3-kinase pathways. J. Neurochem. 78: 435-445.

Dixon, C.E., Hamm, R.J., Taft, W.C., and Hayes, R.L. 1994. Increased anticholinergic sensitivity following closed skull impact and controlled cortical impact traumatic brain injury in the rat. J. Neurotrauma 11: 275-287.

Drain, P., Folkers, E., and Quinn, W.G. 1991. cAMP-dependent protein kinase and the disruption of learning in transgenic flies. Neuron 6: 71-82.

Drier, E.A., Tello, M.K., Cowan, M., Wu, P., Blace, N., Sacktor, T.C., and Yin, J.C. 2002. Memory enhancement and formation by atypical PKM activity in Drosophila melanogaster. Nat. Neurosci. 5: 316-324.

English, J.D. and Sweatt, J.D. 1997. A requirement for the mitogen-activated protein kinase cascade in hippocampal long term potentiation. J. Biol. Chem. 272: 19103-19106.

Gallagher, M., Burwell, R., and Burchinal, M. 1993. Severity of spatial learning impairment in aging: Development of a learning index for performance in the Morris water maze. Behav. Neurosci. 107: 618-626.

Gaullier, J.M., Simonsen, A., D'Arrigo, A., Bremnes, B., Stenmark, H., and Aasland, R. 1998. FYVE fingers bind PtdIns(3)P. Nature 394: 432-433.

Ghirardi, M., Montarolo, P.G., and Kandel, E.R. 1995. A novel intermediate stage in the transition between short- and long- term facilitation in the sensory to motor neuron synapse of Aplysia. Neuron 14: 413-420.

Gillooly, D.J., Simonsen, A., and Stenmark, H. 2001. Cellular functions of phosphatidylinositol 3-phosphate and FYVE domain proteins. Biochem. J. 355: 249-258.

Hagiwara, M., Brindle, P., Harootunian, A., Armstrong, R., Rivier, J., Vale, W., Tsien, R., and Montminy, M.R. 1993. Coupling of hormonal stimulation and transcription via the cyclic AMP- responsive factor CREB is rate limited by nuclear entry of protein kinase A. Mol. Cell. Biol. 13: 4852-4859.
Hunter, T. 1995. When is a lipid kinase not a lipid kinase? When it is a protein kinase. Cell 83: 1-4.

Izzard, R.A., Jackson, S.P., and Smith, G.C. 1999. Competitive and noncompetitive inhibition of the DNA-dependent protein kinase. Cancer Res. 59: 2581-2586.

Jun, K., Choi, G., Yang, S.G., Choi, K.Y., Kim, H., Chan, G.C., Storm, D.R., Albert, C., Mayr, G.W., Lee, C.J. et al. 1998. Enhanced hippocampal CA1 LTP but normal spatial learning in inositol 1,4,5-trisphosphate 3-kinase(A)-deficient mice. Learn. Mem. 5: 317-330.

Kelly, A. and Lynch, M.A. 2000. Long-term potentiation in dentate gyrus of the rat is inhibited by the phosphoinositide 3-kinase inhibitor, wortmannin. Neuropharmacology 39: 643-651.

Kim, J.J., Fanselow, M.S., DeCola, J.P., and Landeira-Fernandez, J. 1992. Selective impairment of long-term but not short-term conditional fear by the N-methyl-D-aspartate antagonist APV. Behav. Neurosci. 106: $591-596$

Lin, C.H., Yeh, S.H., Lu, K.T., Leu, T.H., Chang, W.C., and Gean, P.W 2001. A role for the PI-3 kinase signaling pathway in fear conditioning and synaptic plasticity in the amygdala. Neuron 31: 841-851.

Malleret, G., Haditsch, U., Genoux, D., Jones, M.W., Bliss, T.V., Vanhoose, A.M., Weitlauf, C., Kandel, E.R., Winder, D.G., and Mansuy, I.M. 2001 Inducible and reversible enhancement of learning, memory, and long-term potentiation by genetic inhibition of calcineurin. Cell 104: 675-686

Martin, K.C., Michael, D., Rose, J.C., Barad, M., Casadio, A., Zhu, H., and Kandel, E.R. 1997. MAP kinase translocates into the nucleus of the presynaptic cell and is required for long-term facilitation in Aplysia. Neuron 18: 899-912.

Moelling, K., Schad, K., Bosse, M., Zimmermann, S., and Schweneker, M. 2002. Regulation of Raf-Akt cross-talk. J. Biol. Chem. DOI 10.1074/ jbc.M111974200.

Morris, R.G., Garrud, P., Rawlins, J.N., and O'Keefe, J. 1982. Place navigation impaired in rats with hippocampal lesions. Nature 297: 681-683

Morris, R.G., Anderson, E., Lynch, G.S., and Baudry, M. 1986. Selective impairment of learning and blockade of long-term potentiation by an N-methyl-D-aspartate receptor antagonist, AP5. Nature 319: 774-776.

Moser, E., Moser, M.B., and Andersen, P. 1993. Spatial learning impairment parallels the magnitude of dorsal hippocampal lesions, but is hardly present following ventral lesions. J. Neurosci. 13: 3916-3925.

Netto, C.A., Hodges, H., Sinden, J.D., Le Peillet, E., Kershaw, T., Sowinski, P., Meldrum, B.S., and Gray, J.A. 1993. Effects of fetal hippocampal field grafts on ischaemic-induced deficits in spatial navigation in the water maze. Neurosci. 54: 69-92.

Phillips, R.G. and LeDoux, J.E. 1992. Differential contribution of amygdala and hippocampus to cued and contextual fear conditioning. Behav Neurosci. 106: 274-285.

Raymond, C.R., Redman, S.J., and Crouch, M.F. 2002. The phosphoinositide 3-kinase and p70 $\mathrm{S} 6$ kinase regulate long-term potentiation in hippocampal neurons. Neuroscience 109: 531-536.

Rudy, J.W. and O'Reilly, R.C. 1999. Contextual fear conditioning, conjunctive representations, pattern completion, and the hippocampus. Behav. Neurosci. 113: 867-880.

Sanna, P.P., Cammalleri, M., Berton, F., Simpson, C., Lutjens, R., Bloom, F.E., and Francesconi, W. 2002. Phosphatidylinositol 3-kinase is required for the expression but not for the induction or the maintenance of long-term potentiation in the hippocampal CA1 region. J. Neurosci. 22: 3359-3365.

Soderling, T.R. and Derkach, V.A. 2000. Postsynaptic protein phosphorylation and LTP. Trends Neurosci. 23: 75-80.

Squire, L.R. 1992. Memory and the hippocampus: a synthesis from findings with rats, monkeys, and humans. Psychol. Rev. 99: 195-231.

Sutton, M.A., Ide, J., Masters, S.E., and Carew, T.J. 2002. Interaction between amount and pattern of training in the induction of intermediate- and long-term memory for sensitization in aplysia. Learn. Mem. 9: 29-40.

Toker, A. and Cantley, L.C. 1997. Signalling through the lipid products of phosphoinositide-3-OH kinase. Nature 387: 673-676.

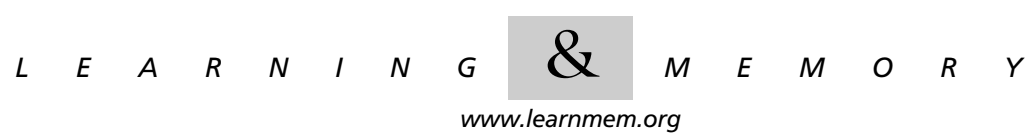


Vanhaesebroeck, B., Leevers, S.J., Panayotou, G., and Waterfield, M.D. 1997. Phosphoinositide 3-kinases: A conserved family of signal transducers. Trends Biochem. Sci. 22: 267-272.

Withers, D.J., Ouwens, D.M., Nave, B.T., van der Zon, G.C., Alarcon, C.M., Cardenas, M.E., Heitman, J., Maassen, J.A., and Shepherd, P.R. 1997. Expression, enzyme activity, and subcellular localization of mammalian target of rapamycin in insulin-responsive cells. Biochem. Biophys. Res. Commun. 241: 704-709.

Yin, J.C., Wallach, J.S., Del Vecchio, M., Wilder, E.L., Zhou, H., Quinn, W.G., and Tully, T. 1994. Induction of a dominant negative CREB transgene specifically blocks long-term memory in Drosophila. Cell 79: 49-58.

Yin, J.C., Del Vecchio, M., Zhou, H., and Tully, T. 1995. CREB as a memory modulator: Induced expression of a dCREB2 activator isoform enhances long-term memory in Drosophila. Cell 81: 107-115.

York, R.D., Molliver, D.C., Grewal, S.S., Stenberg, P.E., McCleskey, E.W., and Stork, P.J. 2000. Role of phosphoinositide 3-kinase and endocytosis in nerve growth factor-induced extracellular signal-regulated kinase activation via Ras and Rap1. Mol. Cell. Biol. 20: 8069-8083.

Zhao, W.Q., Polya, G.M., Wang, B.H., Gibbs, M.E., Sedman, G.L., and Ng, K.T. 1995. Inhibitors of cAMP-dependent protein kinase impair long-term memory formation in day-old chicks. Neurobiol. Learn. Mem. 64: 106-118.

Zola-Morgan, S., Squire, L.R., and Amaral, D.G. 1986. Human amnesia and the medial temporal region: Enduring memory impairment following a bilateral lesion limited to field CA1 of the hippocampus. J. Neurosci. 6: $2950-2967$

Received May 1, 2002; accepted in revised form June 26, 2002. 


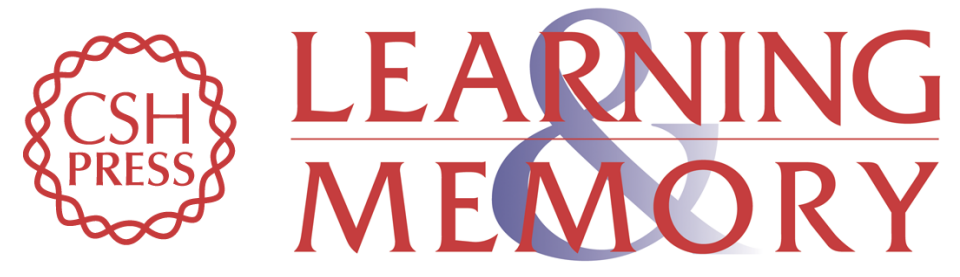

\section{Intrahippocampal Wortmannin Infusion Enhances Long-Term Spatial and Contextual Memories}

Pramod K. Dash, Sara A. Mach, Sonja Blum, et al.

Learn. Mem. 2002, 9:

Access the most recent version at doi:10.1101/lm.50002

References This article cites 47 articles, 13 of which can be accessed free at: http://learnmem.cshlp.org/content/9/4/167.full.html\#ref-list-1

License

Email Alerting Receive free email alerts when new articles cite this article - sign up in the box at the Service top right corner of the article or click here. 